\title{
Inhaled Iloprost Versus Epoprostenol in Heart Transplant Recipients
}

\author{
T Miko Enomoto, Miriam M Treggiari, N David Yanez, and \\ Matthias J Merkel
}

\begin{abstract}
BACKGROUND: Acute right ventricular dysfunction is a challenging problem in the immediate postoperative period following orthotopic heart transplantation. There are no prior reports of the use of inhaled iloprost in the setting of acute right ventricular dysfunction and acute pulmonary hypertension. Our hypothesis was that the use of inhaled iloprost in heart transplant recipients would be associated with a reduction in the duration of mechanical ventilation compared to patients being treated with continuous inhaled epoprostenol. Additionally, we hypothesized that the change in inhaled vasodilatory therapy would not be associated with a significant change in postoperative bleeding or use of vasoactive medications. METHODS: We reviewed charts of 80 consecutive patients undergoing heart transplantation at our institution between July 1, 2003, and August 8, 2008. From July 1, 2003 to March 13, 2006, epoprostenol was our primary vasodilator; subsequently epoprostenol was replaced with iloprost. We included 39 subjects who received epoprostenol and 40 subjects who received iloprost. Data were collected on the use of inhaled vasodilators, comparing periods before and after our institutional protocol change. Demographic data, hemodynamic values, drain output, and any requirement for vasoactive medication infusions were collected. Our primary end point was the natural logarithm of duration of mechanical ventilation. Secondary end points were hemodynamic values and length of ICU and hospital stay. RESULTS: Subjects treated with iloprost were mechanically ventilated for $0.36 \pm 0.20$ (adjusted mean \pm SE) $\log$ days, which was shorter $(P=.033)$ than the $1.00 \pm 0.22$ logdays for subjects treated with epoprostenol. This resulted in an estimated median number of mechanically ventilated days for subjects treated with epoprostenol that was approximately 1.9 times longer than the estimated median number of ventilated days for subjects treated with iloprost (95\% CI 1.05-3.4, $P=.033$ ). There were no differences in safety end points or length of hospital stay. CONCLUSIONS: Use of inhaled iloprost was associated with shorter duration of mechanical ventilation compared to inhaled epoprostenol, without safety concerns. Key words: heart transplantation; vasodilator agents; hypertension; pulmonary; iloprost; prostaglandins; synthetic; right-sided heart failure. [Respir Care 2019;64(7):743-751. @ 2019 Daedalus Enterprises]
\end{abstract}

\section{Introduction}

Acute right ventricular dysfunction remains one of the most challenging problems in the immediate postoperative period following orthotopic heart transplantation. It has been reported that right ventricular dysfunction accounted for $50 \%$ of all cardiac complications and $19 \%$ of all early deaths in patients after heart transplantation. ${ }^{1}$ Mastouri et $\mathrm{al}^{2}$ found that all subjects had severe right ventricular dysfunction in the first two weeks following transplant. Acute pulmonary hypertension with acute increase in pul-

\footnotetext{
This study was supported by unrestricted grant from Actelion Pharmaceuticals US. The authors have disclosed no other conflicts of interest.

Supplementary material related to this paper is available at http:// www.rcjournal.com.
} 
monary vascular resistance plays a key role in the development and possible progression of acute right ventricular dysfunction to failure. ${ }^{3}$

See the Related Editorial on Page 864

Common management strategies to overcome acute right ventricular dysfunction include volume optimization, ensuring adequate coronary perfusion pressures with vasopressors, and use of high doses of inotropic agents. ${ }^{4}$ In addition, tachycardia, achieved with chronotropic agents or electrically pacing, is often used to reduce the likelihood of right ventricular dilation. Inhaled vasodilators, like inhaled nitric oxide and inhaled epoprostenol (prostacyclin), have been successfully used to decrease pulmonary vascular resistance, thereby decreasing right ventricular afterload and increasing right ventricular output. De Wet et $\mathrm{al}^{5}$ demonstrated that epoprostenol is an efficacious and cost-effective alternative to nitric oxide for management of post-cardiac surgery pulmonary hypertension. Epoprostenol has been shown to reduce cost associated with the management of pulmonary hypertension, right heart dysfunction, and refractory hypoxemia after cardiothoracic surgery. Khan et $\mathrm{al}^{6}$ showed that inhaled nitric oxide and epoprostenol are similarly efficacious in decreasing pulmonary arterial pressure and central venous pressure, and increasing cardiac index and mixed venous oxygen saturation in a small population of heart recipients and single- and double-lung recipients immediately following transplantation.

Unfortunately, both inhaled nitric oxide and epoprostenol have drawbacks. Inhaled nitric oxide requires continuous delivery to an intubated patient, ${ }^{7-9}$ monitoring for toxic metabolites, ${ }^{7,8,10,11}$ and is costly. ${ }^{5,12,13}$ The short halflives of both medications can result in significant and dangerous hemodynamic perturbation if delivery is disrupted, increasing the likelihood of acute right ventricular failure. This makes less invasive and less reliable routes of inhalational therapy (eg, face mask, nasal cannula) very risky. Although less expensive, inhaled epoprostenol also requires continuous delivery, and frequent changes of ventilator filters are necessary with some brands of epoprostenal to prevent barotrauma resulting from "sticky" valves, which are caused by the glycine diluent. ${ }^{5}$

Iloprost is a long-acting prostacyclin analog with clinical activity that lasts $60-120$ min after administration. ${ }^{13}$

Correspondence: Miriam M Treggiari MD PhD MPH, 3181 SW Sam Jackson Park Road, Mail Code UHN-2, Portland, OR 97239. E-mail: treggiar@ohsu.edu.

DOI: $10.4187 /$ respcare. 06426

\section{QUICK LOOK}

\section{Current knowledge}

Acute right ventricular dysfunction is a challenging problem in the immediate postoperative period following orthotopic heart transplantation. There are no prior reports of the use of inhaled iloprost in the setting of acute right ventricular dysfunction and acute pulmonary hypertension.

\section{What this paper contributes to our knowledge}

Inhaled iloprost was associated with a shorter duration of invasive ventilation compared to epoprostenol. There were no clinically relevant differences in hemodynamic values, and no differences in ICU and hospital stay. Iloprost may be an acceptable alternative to epoprostenol as an inhaled vasodilator following heart transplantation, and it may offer clinically meaningful advantages.

This longer duration allows for intermittent dosing and is more conducive for administration to an extubated patient, to whom it can be given using the same nebulizer connected to either an aerosol mask or mouthpiece. ${ }^{14}$ Inhaled iloprost's approved indication is for treating chronic pulmonary hypertension. As far as we are aware, there are no prior reports of the use of inhaled iloprost in the setting of acute right ventricular dysfunction and acute pulmonary hypertension. At our institution, inhaled iloprost therapy has been used after orthotopic heart transplantation for managing acute pulmonary hypertension or acute right ventricular failure.

Our purpose was to evaluate the clinical practice of using inhaled iloprost compared to a historical cohort that received continuous inhaled vasodilator therapy with epoprostenol following orthotopic heart transplantation. We hypothesized that the use of inhaled iloprost was associated with shorter duration of invasive ventilation and ICU stay. We also investigated the safety of inhaled iloprost as measured by hemodynamic profiles and the requirement for vasoactive infusions or bleeding complications. We hypothesized that the use of inhaled iloprost in heart transplant recipients was associated with a shorter duration of mechanical ventilation and ICU length of stay compared to patients being treated with continuous inhaled epoprostenol. We also investigated potential complications associated with inhaled iloprost as measured by hemodynamic profiles, the requirement for vasoactive medications, and postoperative bleeding. 


\section{Methods}

\section{Study Population}

The study was performed at Oregon Health \& Science University, a regional referral center for cardiac transplantation and advanced heart failure therapies. After obtaining institutional review board approval, we reviewed consecutive patients undergoing orthotopic heart transplantation between July 1, 2003, and August 8, 2008. The protocol for the use of inhaled iloprost was introduced in clinical practice on March 13, 2006, when the use of epoprostenol ended. There was no time overlap between the discontinuation of inhaled epoprostenol and the introduction of iloprost. Patients were excluded from the study if they had received both epoprostenol and iloprost. Thus, patients received only inhaled epoprostenol or inhaled iloprost.

\section{Study Design}

This was a retrospective cohort study comparing subjects exposed to inhaled iloprost to subjects exposed to inhaled epoprostenol. Subjects who received epoprostenol in the historic cohort were assigned to the epoprostenol group; subjects who received iloprost from March 14, 2006, to August 8, 2008 were assigned to the iloprost group. Subjects who were not treated with either inhaled vasodilator during each respective period were included in this investigation to evaluate for temporal trends over the 2 study periods. We defined "control group 1" as the unexposed cohort of subjects transplanted during the period of epoprostenol use, and "control group 2" as the unexposed cohort transplanted during the iloprost use period.

\section{Protocol for the Administration of Epoprostenol and Iloprost}

The indications for use of either inhaled vasodilators were similar in the 2 periods and included emergent right ventricular failure with shock (cardiac index $<2 \mathrm{~L} / \mathrm{min} / \mathrm{m}^{2}$ ), mean pulmonary arterial pressure $>30 \mathrm{~mm} \mathrm{Hg}$, left ventricular assist device implantation, and elevated mean pulmonary arterial pressure after cardiac surgery (see the supplementary materials at http://www.rcjournal.com). Patients were ineligible for the use of inhaled agents if pregnant or if their age was $\leq 17 \mathrm{y}$. Institutional guidelines listed active and significant bleeding, thrombocytopenia, and right ventricular failure secondary to left ventricular failure as relative contraindications to the use of either inhaled vasodilator. Ultimately, treatment decisions were made by the clinical care team.

Our institutional guidelines for the use of inhaled epoprostenol followed those published by De Wet et $\mathrm{al}^{5}$ with a starting dose of $10,000 \mathrm{ng} / \mathrm{mL}$ for patients weighing $<80 \mathrm{~kg}$ and $20,000 \mathrm{ng} / \mathrm{mL}$ for patients weighing $\geq 80 \mathrm{~kg}$. Epoprostenol (Flolan, GlaxoSmithKline, Research Triangle Park, North Carolina) was delivered via syringe pump using a MiniHEART nebulizer (Westmed, Tucson, Arizona) at a constant flow of $8 \mathrm{~mL} / \mathrm{h}$, equivalent to $80,000 \mathrm{ng} / \mathrm{h}$ for subjects weighing $<80 \mathrm{~kg}$. The nebulizer was connected to oxygen at a constant flow of $2-3 \mathrm{~L} / \mathrm{min}$ and placed in the inspiratory limb of the ventilator circuit. The expiratory limb filter was changed every $2 \mathrm{~h}$ during epoprostenol administration, and PEEP levels were monitored carefully to evaluate for evidence of inadvertent PEEP elevation due to clogging of filters or expiratory valve malfunction. Hemodynamic variables were monitored and recorded every $30 \mathrm{~min}$ for the duration of therapy.

The recommended starting dose for inhaled iloprost was $10 \mu \mathrm{g}$ inhaled over $15 \mathrm{~min}$ and re-dosed every $90-120 \mathrm{~min}$ with hold parameters if mean pulmonary arterial pressure was below target value $(<30 \mathrm{~mm} \mathrm{Hg})$. Iloprost was delivered as aerosolized administration via a special membrane-based nebulizer (Aerogen, Mountain View, California) placed into the inspiratory limb.

An active heated-wire ventilator circuit was used instead of a passive humidifier to reduce risk of flow obstruction during the inhalation period in all subjects receiving either of the 2 inhaled vasodilator therapies. For all subjects, hemodynamic variables were monitored and recorded every $30 \mathrm{~min}$ for the initial $4 \mathrm{~h}$ of therapy and then hourly per critical care standard.

With the administration of either inhaled vasodilator, the response to the therapy was assessed based on its indication, either as an increase in cardiac index $>15 \%$, or as a decrease in pulmonary vascular resistance or mean pulmonary arterial pressure by $\geq 15 \%$ within $30 \mathrm{~min}$ of initiation of therapy. If the treatment did not meet these thresholds, the protocol recommended discontinuation of therapy.

\section{Study Procedures}

Our study primary end point was the natural logarithm of duration of mechanical ventilation, defined as the duration of the first ventilation event, with start time at ICU admission and end time at the first successful extubation. Failed extubation was defined as the need for re-intubation or tracheostomy within $48 \mathrm{~h}$ of prior extubation. Secondary end points included the natural logarithm of the ICU and hospital length of stays. ICU length of stay was defined as the duration of the first ICU admission event. Readmissions to the ICU within $24 \mathrm{~h}$ were considered part of the same ICU admission. Other secondary end points included the averaged postoperative mean pulmonary arterial pressure and mean arterial pressure, and central venous pressure.

We collected demographic and baseline characteristics including age, gender, body mass index, comorbidities (ie, chronic kidney disease), need for mechanical hemodynamic 
support, creatinine, hematocrit, and platelets counts. We also collected preoperative and intraoperative measures of cardiac index, mean pulmonary arterial pressure, pulmonary vascular resistance, mean arterial pressure, and central venous pressure, as well as postoperative data on use and type of inhalational vasodilator.

To evaluate the safety of the inhalational agents, we collected pre-, intra- and postoperative hemodynamic data including vasoactive infusions, laboratory data, and daily chest-tube drainage. We separately computed the use of phenylephrine, norepinephrine, epinephrine, vasopressin, and isoproterenol for each of the first 5 successive postoperative days. Daily chest-tube drainage was calculated as the 24-h total for each of the first 2 postoperative days.

\section{Statistical Analysis}

Demographic and baseline characteristics were compared between the 2 control groups and the 2 inhaled vasodilator groups. We employed regression analysis with robust (sandwich) standard error estimates to compare means for quantitative characteristics and Fisher exact tests for binary variables. For the analysis of the primary end point, duration of mechanical ventilation, we used multivariable linear regression analysis with robust variance estimates. We tested differences between the inhaled vasodilator groups (a) and the control groups (b) as adjusted pairwise comparisons. Similarly, we used multivariable regression analysis to evaluate the secondary end points and the safety end points. We performed bootstrap analyses ${ }^{15}$ to consider whether any of the sampling distributions of mean estimates were non-normal. All the bootstrap sampling distributions appeared approximately normal.

The summary statistics of interest are mean comparisons of the outcomes between the treatment groups (ie, iloprost and epoprostenol). Because the outcomes are logtransformed, the inverse of the log-transformed mean differences between the treatment groups can be interpreted as the ratio of the treatment groups' respective median estimates. Analyses for these outcomes and the occurrence of complications were adjusted for subject age, gender, preoperative cardiac index, whether the patient was mechanically ventilated, and their baseline inotropic medication use. All hypothesis tests, associated $P$ values, and confidence intervals are 2-sided. Statistical analyses were performed using the Stata version 13.1 (StataCorp, College Station, Texas) and R version 3.3.1 (R Foundation, Vienna, Austria) statistical packages.

\section{Results}

During the study period, 80 patients underwent orthotopic heart transplantation (Fig. 1). One patient received both epoprostenol and iloprost and was excluded. Our ret-

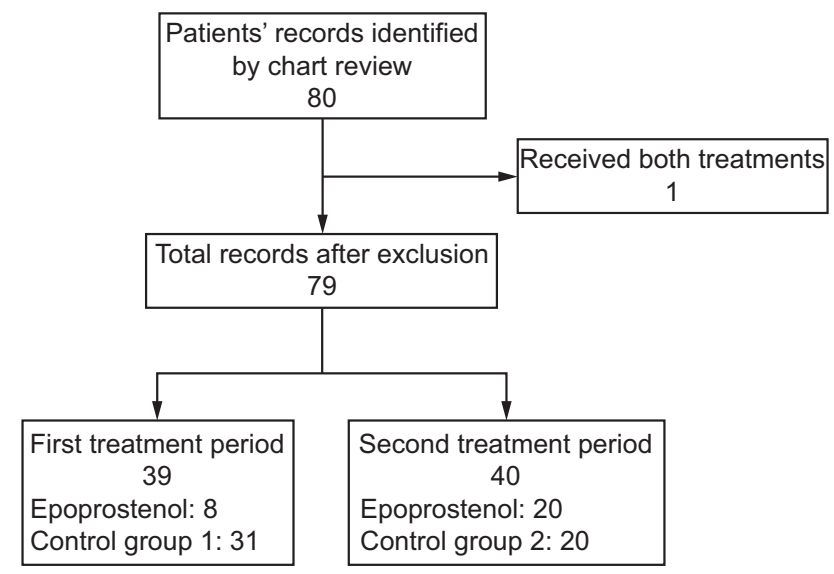

Fig. 1. Flow chart.

rospective analysis did not identify any subjects in either inhaled vasodilator group who had relative contraindications to the use of inhaled agents. Subject baseline demographic and hemodynamic characteristics across the exposed and concurrent control groups are summarized in Table 1. Only the preoperative cardiac index differed between the 2 inhaled vasodilator groups, with 2.4 (SD 0.6) for the iloprost group and 3.2 (SD 0.9) for the epoprostenol group $(P=.038)$. For the 2 concurrent control groups, 16 of the 19 characteristics were similar. Preoperative inotropic support, intraoperative mean arterial pressure, and preoperative central venous pressure differed between the control groups. No instances of nebulizer failure or failure to deliver the inhaled vasodilator were identified.

\section{Primary End Point: Duration of Mechanical Ventilation}

Table 2 presents the unadjusted mean estimates and standard errors for the number of mechanical-ventilation days (log scale) for the exposed and control groups. The mean estimate of mechanical-ventilation days for the epoprostenol group was longer compared with the iloprost group, while the 2 control groups had similar duration of mechanical ventilation. Table 2 also presents the formal adjusted pairwise comparisons between the inhaled vasodilator groups and the control groups. The estimated median number of mechanically ventilated days for subjects treated with epoprostenol was approximately 1.9 times larger than the median number of mechanically ventilated days for subjects treated with iloprost (estimate of mean difference -0.64 , SE $0.3, P=.033$, Fig. 2). While there was a significant association between the inhaled-vasodilator group and mechanical-ventilation days, the estimated difference in mechanical-ventilation days for the 2 concurrent control groups was not appreciably different $(P=.34)$. 
Table 1. Baseline Characteristics of Inhaled Vasodilator and Control Groups

\begin{tabular}{|c|c|c|c|c|c|c|c|}
\hline \multirow{2}{*}{ Variables } & \multicolumn{2}{|c|}{$\begin{array}{l}\text { Iloprost } \\
(n=20)\end{array}$} & \multicolumn{2}{|c|}{$\begin{array}{c}\text { Epoprostenol } \\
\quad(n=8)\end{array}$} & \multicolumn{3}{|c|}{$\begin{array}{l}\text { Iloprost - Epoprostenol } \\
\text { Mean Difference }\end{array}$} \\
\hline & Mean* & SD & Mean* & SD & Difference & SE & $P$ \\
\hline \multicolumn{8}{|l|}{ Inhaled Vasodilator Groups } \\
\hline Age, y & 44.8 & 15.2 & 51.8 & 12.9 & -7.0 & 5.6 & .21 \\
\hline Male $\dagger$ & 16 & $80 \%$ & 8 & $100 \%$ & ND & ND & .30 \\
\hline Body mass index, $\mathrm{kg} / \mathrm{m}^{2}$ & 26.4 & 6.0 & 28.6 & 5.7 & -2.2 & 2.3 & .35 \\
\hline Chronic kidney disease (creatinine $\geq 2 \mathrm{mg} / \mathrm{dL}$ ) $\dagger$ & 1 & $5 \%$ & 0 & $0 \%$ & ND & ND & $>.99$ \\
\hline Cardiac index, preoperative & 2.4 & 0.6 & 3.2 & 0.9 & -0.8 & 0.4 & .038 \\
\hline Cardiac index, intraoperative & 3.4 & 0.9 & 3.7 & 1.0 & -0.3 & 0.4 & .52 \\
\hline Mean pulmonary arterial pressure, preoperative, $\mathrm{mm} \mathrm{Hg}$ & 32.8 & 11.1 & 34.6 & 12.7 & -1.8 & 5.0 & .72 \\
\hline Mean pulmonary arterial pressure, intraoperative, $\mathrm{mm} \mathrm{Hg}$ & 26.6 & 6.2 & 26.7 & 5.4 & -0.2 & 2.4 & .95 \\
\hline Pulmonary vascular resistance, preoperative, Wood units & 3.7 & 2.2 & 3.5 & 2.2 & 0.1 & 0.9 & .89 \\
\hline Creatinine, preoperative, $\mathrm{mg} / \mathrm{dL}$ & 1.3 & 0.4 & 1.3 & 0.4 & 0.0 & 0.1 & .92 \\
\hline Hematocrit, preoperative & 35.8 & 5.0 & 39.6 & 7.4 & -3.9 & 2.8 & .17 \\
\hline Platelets, preoperative, $\times 10^{9} / \mathrm{L}$ & 250.3 & 76.2 & 219.8 & 45.0 & 30.6 & 22.9 & .19 \\
\hline INR, preoperative & 1.7 & 0.7 & 1.7 & 0.7 & 0.0 & 0.3 & .91 \\
\hline Mean arterial pressure, preoperative & 78.2 & 13.5 & 89.3 & 14.3 & -11.0 & 5.8 & .063 \\
\hline Mean arterial pressure, intraoperative & 65.3 & 9.8 & 70.4 & 9.8 & -5.1 & 4.0 & .20 \\
\hline Central venous pressure, preoperative & 10.8 & 5.9 & 11.1 & 5.8 & -0.3 & 2.4 & .91 \\
\hline Central venous pressure, intraoperative & 14.9 & 4.7 & 15.4 & 5.3 & -0.6 & 2.3 & .81 \\
\hline Preoperative inotropic support $\dagger$ & 7 & $35 \%$ & 0 & $0 \%$ & ND & ND & .08 \\
\hline \multirow[t]{2}{*}{ Preoperative mechanical support $\dagger$} & 3 & $15 \%$ & 2 & $25 \%$ & ND & ND & .61 \\
\hline & \multicolumn{2}{|c|}{$\begin{array}{l}\text { Control } 1 \\
(n=20)\end{array}$} & \multicolumn{2}{|c|}{$\begin{array}{l}\text { Control } 2 \\
(n=31)\end{array}$} & \multicolumn{3}{|c|}{$\begin{array}{c}\text { Control } 1 \text { - Control } 2 \\
\text { Mean Difference }\end{array}$} \\
\hline \multicolumn{8}{|l|}{ Control Groups } \\
\hline Age, y & 47.0 & 13.3 & 45.4 & 17.2 & 1.6 & 4.5 & .73 \\
\hline Male $\dagger$ & 24 & $77 \%$ & 15 & $75 \%$ & ND & ND & $>.99$ \\
\hline Body mass index, $\mathrm{kg} / \mathrm{m}^{2}$ & 26.0 & 4.5 & 28.2 & 4.6 & -2.2 & 1.4 & .11 \\
\hline Chronic kidney disease (creatinine $\geq 2 \mathrm{mg} / \mathrm{dL}$ ) $\dagger$ & 2 & $6 \%$ & 1 & $5 \%$ & ND & $\mathrm{ND}$ & $>.99$ \\
\hline Cardiac index, preoperative & 2.6 & 0.8 & 2.8 & 0.6 & -0.2 & 0.2 & .35 \\
\hline Cardiac index, intraoperative & 3.6 & 0.8 & 3.9 & 0.8 & -0.4 & 0.3 & .15 \\
\hline Mean pulmonary arterial pressure, preoperative, $\mathrm{mm} \mathrm{Hg}$ & 33.6 & 10.7 & 31.4 & 8.1 & 2.2 & 2.7 & .42 \\
\hline Mean pulmonary arterial pressure, intraoperative, $\mathrm{mm} \mathrm{Hg}$ & 26.3 & 6.5 & 26.6 & 4.4 & -0.4 & 1.7 & .84 \\
\hline Pulmonary vascular resistance, preoperative, Wood units & 2.5 & 1.6 & 2.3 & 1.5 & 0.2 & 0.5 & 69 \\
\hline Creatinine, preoperative, $\mathrm{mg} / \mathrm{dL}$ & 1.3 & 0.4 & 1.2 & 0.4 & 0.0 & 0.1 & .78 \\
\hline Hematocrit, preoperative, $\%$ & 35.3 & 5.5 & 34.0 & 5.3 & 1.3 & 1.6 & .43 \\
\hline Platelets, preoperative & 260.2 & 90.7 & 248.6 & 86.3 & 11.6 & 26.1 & .66 \\
\hline INR, preoperative & 1.8 & 1.2 & 1.4 & 0.4 & 0.4 & 0.3 & .10 \\
\hline Mean arterial pressure, preoperative, $\mathrm{mm} \mathrm{Hg}$ & 71.3 & 15.3 & 69.2 & 10.8 & 2.1 & 4.0 & .59 \\
\hline Mean arterial pressure, intraoperative, $\mathrm{mm} \mathrm{Hg}$ & 68.9 & 10.6 & 62.4 & 8.7 & 6.5 & 2.7 & .02 \\
\hline Central venous pressure, preoperative, $\mathrm{mm} \mathrm{Hg}$ & 9.8 & 6.1 & 13.8 & 6.0 & -4.0 & 1.8 & .03 \\
\hline Central venous pressure, intraoperative, $\mathrm{mm} \mathrm{Hg}$ & 12.8 & 4.6 & 15.3 & 4.1 & -2.5 & 1.4 & .068 \\
\hline Preoperative inotropic support $\dagger$ & 9 & $29 \%$ & 13 & $65 \%$ & ND & ND & .02 \\
\hline Preoperative mechanical support $\dagger$ & 6 & $19 \%$ & 6 & $30 \%$ & ND & ND & .50 \\
\hline \multicolumn{8}{|l|}{$\begin{array}{l}\text { * Unadjusted estimates. } \\
\dagger \text { Fisher exact test. } \\
\mathrm{SE}=\text { standard error } \\
\mathrm{ND}=\text { no data } \\
\mathrm{INR}=\text { international normalized ratio. }\end{array}$} \\
\hline
\end{tabular}


Table 2. Outcomes of Inhaled Vasodilator and Control Groups

\begin{tabular}{|c|c|c|c|c|c|c|c|}
\hline \multirow{2}{*}{ Variables } & \multicolumn{2}{|c|}{$\begin{array}{l}\text { Iloprost } \\
(n=20)\end{array}$} & \multicolumn{2}{|c|}{$\begin{array}{c}\text { Epoprostenol } \\
\quad(n=8)\end{array}$} & \multicolumn{3}{|c|}{ Iloprost - Epoprostenol } \\
\hline & $\begin{array}{l}\text { Unadjusted } \\
\text { Mean }\end{array}$ & $\mathrm{SD}$ & $\begin{array}{l}\text { Unadjusted } \\
\text { Mean }\end{array}$ & SD & $\begin{array}{c}\text { Adjusted } \\
\text { Difference }\end{array}$ & SE & $P^{*}$ \\
\hline \multicolumn{8}{|l|}{ Inhaled Vasodilator Groups } \\
\hline Duration of ventilation (raw scale), $d$ & 1.9 & 1.8 & 3.4 & 2.7 & ND & ND & ND \\
\hline Duration of ventilation (log scale), $\mathrm{d}$ & 0.3 & 0.9 & 1.0 & 0.8 & -0.64 & 0.30 & .033 \\
\hline Hospital length of stay (raw scale), d & 26.1 & 12.9 & 25.4 & 10.8 & ND & ND & ND \\
\hline Hospital length of stay (log scale), d & 3.1 & 0.5 & 3.1 & 0.5 & -0.11 & 0.21 & .60 \\
\hline ICU length of stay (raw scale), d & 10.3 & 3.3 & 12.8 & 5.8 & ND & ND & ND \\
\hline ICU length of stay (log scale), d & 2.3 & 0.3 & 2.5 & 0.4 & 0.00 & 0.16 & $>.99$ \\
\hline Mean pulmonary arterial pressure, postoperative, $\mathrm{mm} \mathrm{Hg}$ & 27.0 & 3.9 & 28.5 & 4.9 & -1.50 & 1.94 & .44 \\
\hline Mean arterial pressure, postoperative, $\mathrm{mm} \mathrm{Hg}$ & 75.0 & 5.2 & 69.6 & 3.7 & 5.44 & 1.96 & .007 \\
\hline \multirow[t]{2}{*}{ Central venous pressure average, postoperative, $\mathrm{mm} \mathrm{Hg}$} & 13.3 & 2.6 & 14.3 & 4.3 & -0.27 & 1.75 & .88 \\
\hline & \multicolumn{2}{|c|}{$\begin{array}{l}\text { Control } 1 \\
(n=20)\end{array}$} & \multicolumn{2}{|c|}{$\begin{array}{l}\text { Control } 2 \\
(n=31)\end{array}$} & \multicolumn{3}{|c|}{ Control 1 - Control 2} \\
\hline \multicolumn{8}{|l|}{ Control Groups } \\
\hline Duration of ventilation (raw scale), $\mathrm{d}$ & 1.3 & 1.4 & 1.0 & 0.8 & ND & ND & ND \\
\hline Duration of ventilation (log scale), d & -0.1 & 0.7 & -0.1 & 0.6 & 0.22 & 0.20 & .34 \\
\hline Hospital length of stay (raw scale), d & 27.1 & 37.8 & 34.4 & 21.3 & ND & ND & ND \\
\hline Hospital length of stay (log scale), d & 2.9 & 0.7 & 3.4 & 0.6 & -0.34 & 0.23 & .15 \\
\hline ICU length of stay (raw scale), $d$ & 15.7 & 37.8 & 12.0 & 18.4 & ND & ND & ND \\
\hline ICU length of stay (log scale), d & 2.2 & 0.7 & 2.1 & 0.6 & -0.05 & 0.20 & .80 \\
\hline Mean pulmonary arterial pressure, postoperative, $\mathrm{mm} \mathrm{Hg}$ & 24.8 & 4.3 & 23.5 & 3.7 & 2.32 & 1.33 & .09 \\
\hline Mean arterial pressure, postoperative, $\mathrm{mm} \mathrm{Hg}$ & 74.6 & 4.3 & 72.1 & 5.8 & 2.14 & 1.73 & .22 \\
\hline Central venous pressure average, postoperative, $\mathrm{mm} \mathrm{Hg}$ & 13.5 & 3.7 & 11.8 & 2.4 & 1.99 & 1.07 & .067 \\
\hline \multicolumn{8}{|c|}{$\begin{array}{l}\text { The mean difference represents effect estimates adjusted for subject age, gender, preoperative cardiac index, whether mechanically ventilated, and baseline inotropic medication use. } \\
* \text { Pairwise comparisons. } \\
\mathrm{SE}=\text { standard error. }\end{array}$} \\
\hline
\end{tabular}

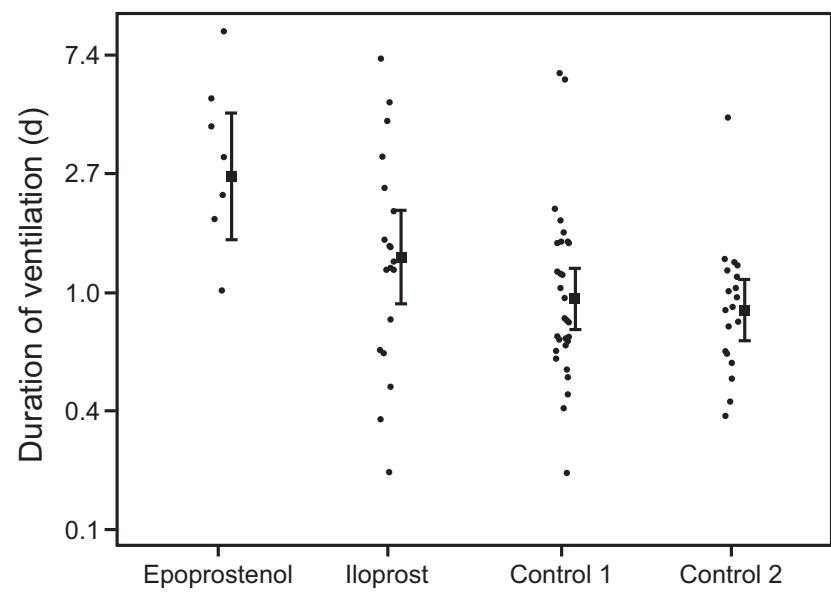

Fig. 2. Ventilation duration by study group and in concurrent cohorts. Data shown as unadjusted $95 \% \mathrm{Cl}$.

\section{Secondary End Points}

Table 2 displays the secondary end points: duration of ICU and hospital length of stay, postoperative mean arte- rial pressure, mean pulmonary arterial pressure, and central venous pressure. Only postoperative mean arterial pressure differed between subjects treated with iloprost and epoprostenol; the adjusted average mean arterial pressure for epoprostenol being approximately $5.44 \mathrm{~mm} \mathrm{Hg}$ lower than the average mean arterial pressure for the iloprost subjects (95\% CI 1.5-9.4, $P=.007)$. There were no differences between the inhaled-vasodilator groups for the other secondary end points. There were no differences between the concurrent control groups for any of these outcomes.

\section{Potential Complications of Inhaled Therapy}

Table 3 provides unadjusted group-level means for each of the potential complications for the study groups and formal adjusted pairwise comparisons between the inhaled vasodilator groups, and between the concurrent control groups. There were no meaningful differences between the inhaled-vasodilator groups in the frequency of use of individual vasoactive infusions. There were differences between the 2 concurrent control groups in 
Table 3. Bleeding and Hypotension Surrogates (Days 1-5) for Inhaled Vasodilator and Control Groups

\begin{tabular}{|c|c|c|c|c|c|c|c|}
\hline \multirow{2}{*}{ Variable (unit) } & \multicolumn{2}{|c|}{ Iloprost $(n=20)$} & \multicolumn{2}{|c|}{ Epoprostenol $(n=8)$} & \multicolumn{3}{|c|}{ Iloprost - Epoprostenol } \\
\hline & Unadjusted Mean & SD & Unadjusted Mean & SD & Adjusted Difference & SE & $P^{*}$ \\
\hline \multicolumn{8}{|l|}{ Inhaled Vasodilator Groups } \\
\hline Use of phenylephrine & 0.6 & 1.2 & 0.5 & 1.4 & -0.2 & 0.7 & .73 \\
\hline Use of norepinephrine & 0.1 & 0.2 & 1.1 & 2.1 & -1.3 & 0.8 & .13 \\
\hline Use of epinephrine & 3.9 & 1.4 & 3.3 & 2.0 & 0.9 & 0.9 & .30 \\
\hline Use of vasopressin & 1.2 & 1.4 & 2.6 & 2.0 & -1.2 & 0.9 & .19 \\
\hline Use of isoproterenol & 2.9 & 2.1 & 1.9 & 1.4 & 0.3 & 0.8 & .66 \\
\hline Use of dobutamine & 1.6 & 2.1 & 3.6 & 2.3 & -2.2 & 1.0 & .034 \\
\hline Use of milrinone & 5.0 & 0.0 & 5.0 & 0.0 & -0.03 & 0.1 & .81 \\
\hline \multirow[t]{2}{*}{ Mediastinal drain total output, $\mathrm{mls}$} & 931 & 1131 & 714 & 328 & 510 & 485 & .30 \\
\hline & \multicolumn{2}{|l|}{$\begin{array}{l}\text { Control } 1 \\
(n=20)\end{array}$} & \multicolumn{2}{|l|}{$\begin{array}{c}\text { Control } 2 \\
(n=31)\end{array}$} & \multicolumn{3}{|c|}{ Control 1 - Control 2} \\
\hline \multicolumn{8}{|l|}{ Control Groups } \\
\hline Use of phenylephrine & 0.3 & 0.6 & 0.3 & 0.8 & 0.1 & 0.2 & .78 \\
\hline Use of norepinephrine & 0.1 & 0.4 & 0.1 & 0.3 & 0.0 & 0.2 & .80 \\
\hline Use of epinephrine & 1.6 & 1.7 & 3.7 & 0.9 & -1.9 & 0.4 & $<.001$ \\
\hline Use of vasopressin & 1.3 & 1.6 & 1.7 & 1.8 & -0.7 & 0.5 & .20 \\
\hline Use of isoproterenol & 3.6 & 2.0 & 3.2 & 1.9 & 0.4 & 0.6 & .51 \\
\hline Use of dobutamine & 4.1 & 1.9 & 0.2 & 1.1 & 4.0 & 0.5 & $<.001$ \\
\hline Use of milrinone & 4.3 & 1.2 & 4.7 & 0.8 & -0.2 & 0.3 & .36 \\
\hline Mediastinal drain total output, mls & 760 & 681 & 688 & 577 & -13 & 200 & .95 \\
\hline \multicolumn{8}{|c|}{$\begin{array}{l}\text { The mean difference represents effect estimates adjusted for patient age, gender, preoperative cardiac index, whether mechanically ventilated, and baseline inotropic medication use. } \\
\text { * Pairwise comparisons. }\end{array}$} \\
\hline
\end{tabular}

the use of epinephrine and dobutamine: control group 1 received epinephrine less frequently than control group 2 (mean difference $1.9,95 \%$ CI $1.1-2.8, P<.001$ ), and control group 1 received dobutamine more frequently than control group 2 (mean difference 4.0, 95\% CI $-3.02-4.98, P<.001)$. There was no difference in the amount of mediastinal drain output between either inhaled vasodilator groups or the concurrent control groups.

\section{Discussion}

Our main finding was that the use of inhaled iloprost for the management of acute right ventricular dysfunction after orthotopic heart transplantation was associated with significantly reduced ventilator days compared to inhaled epoprostenol. This important finding is likely attributable to the use of iloprost because we did not observe relevant differences in the duration of mechanical ventilation among concurrent controls in the 2 study periods. Mechanical ventilation is reported to contribute up to $\$ 1,500$ per day to the cost of an ICU stay. ${ }^{16}$ This financial burden supports efforts to shorten the duration of mechanical ventilation. Furthermore, the use of ilo- prost was associated with higher average mean arterial pressure in the first 5 postoperative days without a difference in the use of vasopressors. The fact that iloprost can be intermittently dosed may avoid some undesirable consequences of continuous administration and may have contributed to the shorter duration of intubation and mechanical ventilation. Intermittent dosing makes iloprost more amenable to administration to an extubated patient, which could contribute to the reduced duration of mechanical ventilation by removing the need for weaning off the inhaled vasodilator. Another favorable feature of inhaled iloprost is that it remains the only prostacyclin with FDA clearance for inhalational therapy.

In clinical practice, we observed that turning patients receiving continuously inhaled epoprostenol was sometimes associated with periods of hypotension. Because consistent dosing of an inhaled liquid requires that the chamber holding the liquid remain stable, it is possible that turning patients during administration of the medication may result in transient relative overdosing of the vasodilator, contributing to systemic hypotension. Because iloprost is dosed intermittently, it is easier to provide routine care such as turns in bed between doses, allowing dosing to be done in a more stable position. 
This may explain the comparatively lower mean arterial pressure observed in the epoprostenol group.

Despite the shorter duration of mechanical ventilation and higher mean arterial pressure with similar vasoactive medication use, the use of iloprost did not translate to a significant differences in the length of ICU or hospital stay compared with the epoprostenol group.

Small trials have suggested that the use of inhaled iloprost lowers acute elevations in pulmonary arterial pressure and is beneficial in the management of acute postoperative pulmonary hypertension and right ventricular dysfunction. ${ }^{17,18}$ Our results support this conclusion. Despite concerns that prostacyclin and its metabolites could cause systemic vasodilation, mean arterial pressure was higher in the group exposed to iloprost compared with epoprostenol. There was no significant difference between groups in the use of vasoconstrictors (ie, vasopressin, phenylephrine, or norepinephrine infusion), suggesting that systemic vasodilatation might have been more pronounced with the continuous administration of epoprostenol. Likewise, subjects in both exposed groups were equally likely to be treated with an inotrope (epinephrine or isoproterenol). However, subjects in the concurrent control group 2 were more likely to receive epinephrine and less likely to receive dobutamine than the earlier cohort. This is likely a reflection of a change in practice from managing chronotropy primarily with pacing to instead allowing intrinsic cardiac rhythm and managing chronotropy with epinephrine. The increasing use of epinephrine, with its potent inotropic effects, could explain the decreasing use of dobutamine. Platelet dysfunction related to prostacyclin and its metabolites is also a potential concern. Mediastinal drain output was collected as a surrogate for postoperative bleeding because platelet dysfunction would presumably increase bleeding. We saw no significant difference in the mediastinal drain output for postoperative days $0-2$ between the treatment groups.

Our study has several limitations. Data collection was done retrospectively, and, as such, not all data points were available. This was not a randomized trial. We used concurrent controls in each study period to account for potential temporal trends that could have been observed over time. Notably, one preoperative variable noted to be different between the inhaled vasodilators groups was the preoperative CI. The mean preoperative CI in the epoprostenol group $\left(3.2 \mathrm{~L} / \mathrm{min} / \mathrm{m}^{2}\right)$ was unusually high for heart failure patients awaiting heart transplant. This was potentially due to the relatively larger proportion of subjects with preoperative mechanical circulatory support (left ventricular assist device), $25 \%$ compared to $15 \%$ in the iloprost group. Therefore, the comparison of 2 groups undergoing care in 2 distinctly different time periods might not have accounted for other changing practice patterns that may occur in parallel. Our study also was unable to control for clin- ical decision-making at the time of initiation of vasodilator therapy, and similarly, the duration of therapy was at the discretion of the treatment teams.

\section{Conclusions}

Despite the shortcomings of our retrospective analysis, it appears that iloprost may be an acceptable alternative to epoprostenol as an inhaled vasodilator following heart transplantation. Iloprost may offer clinically meaningful advantages over continuous epoprostenol, given that intermittent dosing appears to allow for shorter duration of mechanical ventilation.

\section{REFERENCES}

1. Hosenpud JD, Bennett LE, Keck BM, Boucek MM, Novick RJ. The Registry of the International Society for Heart and Lung Transplantation: seventeenth official report-2000. J Heart Lung Transplant 2000;19(10):909-931.

2. Mastouri R, Batres Y, Lenet A, Gradus-Pizlo I, O’Donnell J, Feigenbaum H, Sawada SG. Frequency, time course, and possible causes of right ventricular systolic dysfunction after cardiac transplantation: a single center experience. Echocardiography 2013;30(1):9-16.

3. Dell'Italia LJ. Anatomy and physiology of the right ventricle. Cardiol Clin 2012;30(2):167-187.

4. Ventetuolo CE, Klinger JR. Management of acute right ventricular failure in the intensive care unit. Ann Am Thorac Soc 2014;11(5): 811-822.

5. De Wet CJ, Affleck DG, Jacobsohn E, Avidan MS, Tymkew H, Hill LL, et al. Inhaled prostacyclin is safe, effective, and affordable in patients with pulmonary hypertension, right heart dysfunction, and refractory hypoxemia after cardiothoracic surgery. J Thorac Cardiovasc Surg 2004;127(4):1058-1067.

6. Khan TA, Schnickel G, Ross D, Bastani B, Laks H, Esmailian F, et al. A prospective, randomized, crossover pilot study of inhaled nitric oxide versus inhaled prostacyclin in heart transplant and lung transplant recipients. J Thorac Cardiovasc Surg 2009;138(6): 1417-1424.

7. Creagh-Brown BC, Griffiths MJD, Evans TW. Bench-to-bedside review: inhaled nitric oxide therapy in adults. Crit Care 2009; 13(3):221.

8. Troncy E, Francoeur M, Blaise G. Inhaled nitric oxide: how to deliver it? Crit Care 1998;2(Suppl 1):115.

9. Miller OI, Tang SF, Keech A, Celermajer DS. Rebound pulmonary hypertension on withdrawal from inhaled nitric oxide. Lancet 1995; 346(8966):51-52.

10. Puybasset L, Rouby JJ. Pulmonary uptake and modes of administration of inhaled nitric oxide in mechanically-ventilated patients. Crit Care 1998;2(1):9-17.

11. Weinberger B, Laskin DL, Heck DE, Laskin JD. The toxicology of inhaled nitric oxide. Toxicol Sci 2001;59(11):5-16.

12. McGinn K, Reichert M, Kincaid E, Grosshans D. Inhaled epoprostenol vs inhaled nitric oxide for acute pulmonary hypertension after cardiac surgery. Crit Care Med 2014;42(12):A1508-A1509.

13. Olschewski H, Walmrath D, Schermuly R, Ghofrani A, Grimminger F, Seeger W. Aerosolized prostacyclin and iloprost in severe pulmonary hypertension. Ann Intern Med 1996;124(9):820-824.

14. Olschewski H, Rohde B, Behr J, Ewert R, Gessler T, Ghofrani HA, Schmehl T. Pharmacodynamics and pharmacokinetics of inhaled iloprost, aerosolized by three different devices, in severe pulmonary hypertension. Chest 2003;124(4):1294-1304. 
15. Efron B. The jackknife, the bootstrap and other resampling plans. Philadelphia: Society for Industrial \& Applied Mathematics, 1982.

16. Dasta JF, McLaughlin TP, Piech CT. Daily cost of an intensive care unit day: the contribution of mechanical ventilation. Crit Care Med 2005;33(6):1266-1271.

17. Winterhalter M, Simon A, Fischer S, Rahe-Meyer M, Chamtzidou N, Hecker $\mathrm{H}$, et al. Comparison of inhaled iloprost and nitric oxide in patients with pulmonary hypertension during weaning from cardiopulmonary bypass in cardiac surgery: a prospective randomized trial. J Cardiothorac Vasc Anesth 2008;22(3):406-413.

18. Theodoraki K, Tsiapras D, Tsourelis L, Zarkalis D, Sfirakis P, Kapetanakis $\mathrm{E}$, et al. Inhaled iloprost in eight heart transplant recipients presenting with post-bypass acute right ventricular dysfunction. Acta Anaesthesiol Scand 2006;50(10):1213-1217.

This article is approved for Continuing Respiratory Care Education credit. For information and to obtain your CRCE

(free to AARC members) visit www.rcjournal.com 